\title{
Left Approach for Difficult Laparoscopic Cholecystectomy in Acute Cholecystitis
}

\author{
Hatem EIGohary, ${ }^{1}$ MD, MRCS; Mohamed A. Nada, ${ }^{2}$ MD \\ ${ }^{1}$ Department of General Surgery, Helwan University, Egypt \\ ${ }^{2}$ Department of General Surgery, Faculty of Medicine, Ain Shams University, Egypt
}

Objectives: Laparoscopic cholecystectomy (LC) in acute cholecystitis is challenging especially in the presence of dense inflammatory adhesions and pericholecystic collection. The objective of this study was to evaluate the use of left approach in cases of difficult LC due to acute cholecystitis.

Patients and methods: This was a prospective study done in Badr hospital - Helwan University and in Dar El Shefa hospital - Ministry of Health in Egypt between January 2014 and March 2016 which included 24 patients with difficult LC due to acute cholecystitis. We started the procedure with conventional four ports technique and if failed, we shifted to left approach instead of converting to open surgery. Outcome measures were operative time, rate of conversion to open and intra and post-operative complications.

Results: The mean operative time was 135 minutes and in 1 patient (4\%) the procedure was converted to open surgery due to unclear biliary anatomy. There were no intra-operative complications. Two patients $(8.3 \%)$ in this study had port site infection and 1 patient (4\%) had chest infection on the 3rd postoperative day. Postoperative bile leak was not detected in any of our patients.

Conclusion: The use of left approach technique in LC for difficult cases of acute cholecystitis is effective and safe and further studies should be done to include larger number of patients with different types of difficulties.

Key words: Laparoscopic cholecystectomy, left approach, acute cholecystitis, pericholecystic collection, gall bladder.

\section{Introduction}

Laparoscopiccholecystectomy (LC) isoneof themost common surgical procedures done worldwide and it is the gold standard treatment for gall bladder (GB) diseases. ${ }^{1}$

Although LC has low incidence of morbidity and mortality, its outcome depends on the severity of GB inflammation, patient's age, and sex and body mass index. ${ }^{2}$

Laparoscopic cholecystectomy in acute cholecystitis is challenging especially when it is done after failure of conservative treatment or in the presence of perforated gangrenous GB with dense inflammatory adhesions and pericholecystic collection or abscess.

The determination of difficulty in LC is variable according to surgeon's laparoscopic skills and experience. $\mathrm{LC}$ is rated difficult when the procedure exceeds one and half hour and or converted to open procedure and factors that increase the operative time are adhesions from previous surgery, large stones, very thick GB wall, biliary anomalies and large distended gall bladder. ${ }^{1}$

Difficult LC is associated with increased risk of intra and postoperative complications and high rate of conversion to open surgery. ${ }^{3}$ The low threshold for conversion to open surgery is a good sign for good and safe practice; however conversion to open surgery increases morbidity and cost to the patients. $^{4}$

The aim of this study was to evaluate the effectiveness and safety of left approach LC in cases of difficult LC in acute cholecystitis.

\section{Patients and methods}

This was a prospective study done in Badr hospital - Helwan University and in Dar El Shefa hospital Ministry of Health in Egypt between January 2014 and March 2016 which included 24 patients with difficult LC due to acute cholecystitis. The decision for patient inclusion was taken intraoperative after the trial and failure of conventional procedure. The study was approved by the ethical committee in both hospitals and all patients had written consent before enrollment in the study. 
All patients were subjected to preoperative history taking, thorough clinical examination, pelviabdominal ultrasound, laboratory investigations including liver function tests (ALT, AST, total and direct bilirubin, alkaline phosphatase, GGT and serum amylase), kidney function tests, complete blood picture and coagulation profile (PT, PTT and INR).

The diagnosis of acute cholecystitis was based on theclinical picture of persistentrighthypochondrium and epigastric pain with temperature $>37.5^{\circ} \mathrm{C}$, tenderness and guarding rigidity of upper abdomen, leukocytosis $>10 \times 10^{\circ} / \mathrm{L}$, in addition to positive Murphy's sign, presence of GB wall edema and/or pericholecystic collection on abdominal ultrasound.

Our protocol in management of acute cholecystitis was to initially start conservative treatment for 48 hours by keeping the patient nothing per mouth, intravenous fluids, intravenous antibiotics (third generation cephalosporin combined with metronidazole, NSAIDS, $\mathrm{H} 2$ blockers and antispasmodics.

If the patient improved (decreased pain, fever, tenderness and rigidity of the right hypochondrium), then we performed interval LC after 6 weeks and if the patient did not improve, then we performed emergency LC.

Magnetic resonance cholangiopancreatography (MRCP) was done in patients with history of jaundice, cholangitis, and presence of dilated common bile duct by ultrasound, liver enzymes derangement and in stone passer patients before cholecystectomy.

\section{Operative procedure:}

All patients were operated on by the same surgeons under general anesthesia, in supine $30^{\circ}$ reverse Trendelenburg position with a $10^{\circ}$ tilt to the left. The abdomen was prepared with a disinfectant solution (Betadine) and draped in the usual fashion.

Hasson's technique was routinely used for insufflation of the abdomen and the pressure was kept at $14 \mathrm{mmHg}$.

Nasogastric tube was routinely inserted to deflate the stomach and a third generation cephalosporin (Ceftriaxone) was given at the induction of anaesthesia.

We started the procedure with conventional four ports technique in the form of $10 \mathrm{~mm}$ umbilical port for $30^{\circ}$ scope and another $10 \mathrm{~mm}$ port in the epigastrium two fingers width below xiphisternum and just to the right of the midline and it was used for dissection of Calot's triangle and clipping of the cystic duct and artery. Then, a $5 \mathrm{~mm}$ port was inserted in the right anterior axillary line at the level of the umbilicus for upward traction of the $\mathrm{GB}$ and liver, and another $5 \mathrm{~mm}$ port was inserted in the right mid-clavicular line two fingers width below the costal margin and it was used to retract the Hartman's pouch laterally. (Figure 1).

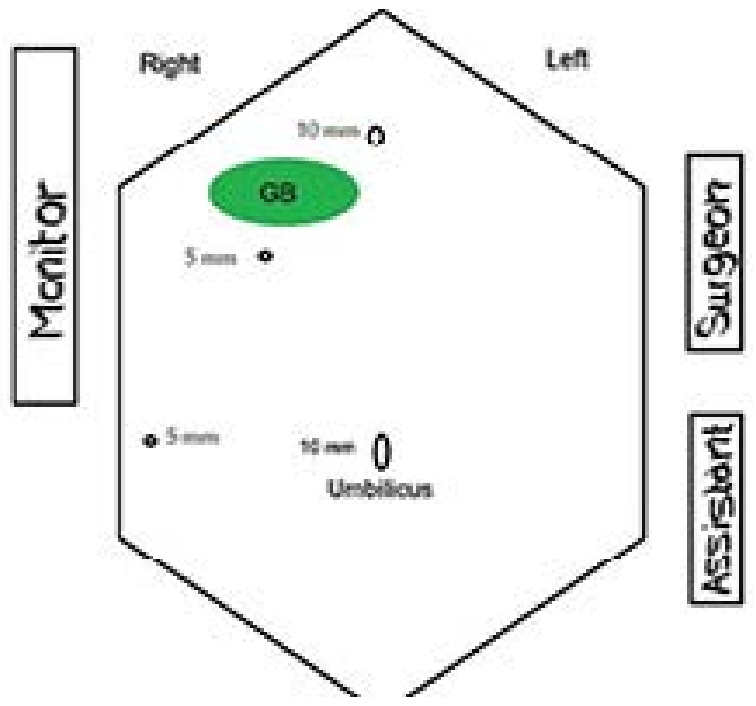

Fig 1: Conventional four ports Laparoscopic Cholecystectomy.

After failure to safely expose and dissect the GB and the Calot's triangle from adhesions with omentum, duodenum or transverse colon, we shifted to left approach instead of converting to open surgery. Two additional $10 \mathrm{~mm}$ ports were inserted in the left mid-clavicular line as shown in Figure $\mathbf{2}$ and Image 1. At this point, the scope was left in place and working through the two left mid-clavicular ports or was shifted to the upper left port for better visualization of the adhesions on the GB with working through the lower left and umbilical ports and the assistant moved cephalad (Images $\mathbf{2} \mathbf{a}, \mathbf{b})$. The right anterior axillary line port was kept for retracting the fundus of the GB upwards. (Figure 2).

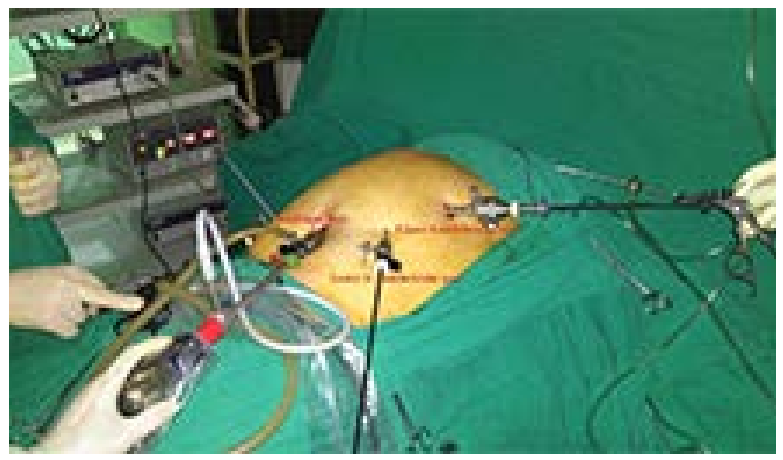

Fig 2: Left approach laparoscopic cholecystectomy

Image 1: Left approach LC ports placement. 


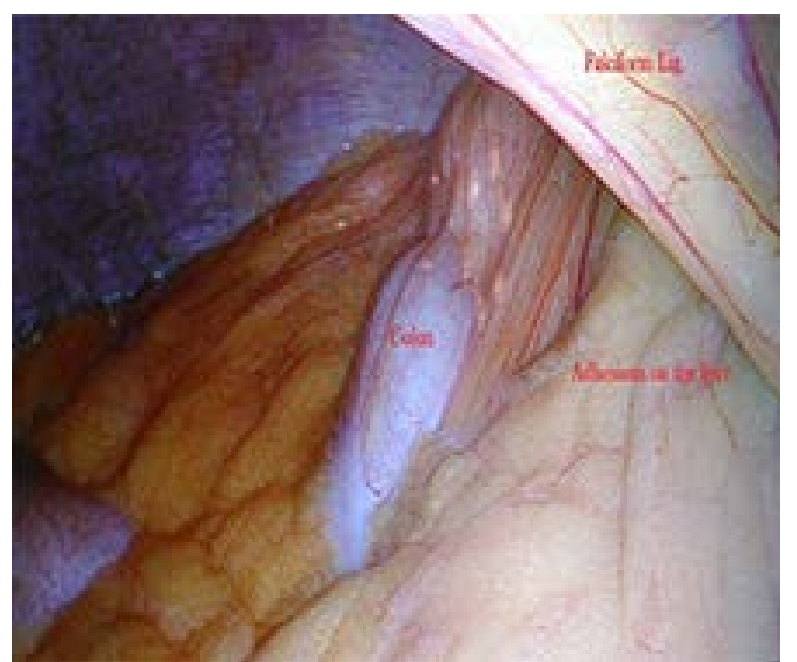

a

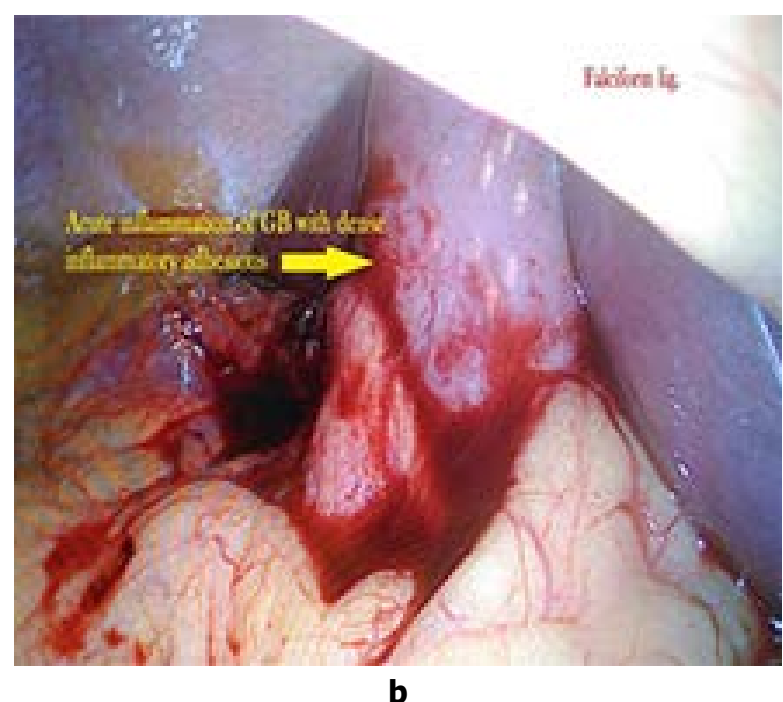

Image 2a,b: Visualization of adhesions from the left upper mid-clavicular port.

Adhesiolysis was done whether blunt by the suction-irrigation instrument or sharp by monopolar electrocautary (Image $\mathbf{3} \mathbf{a}, \mathbf{b}$ ). After releasing all the adhesions around the gall bladder and suction of any present collection, the cystic artery and duct were identified and then divided between three clips (two on the stump and one on the GB) (Image 4). The dissection and removal of GB from the liver was done with electro cautery and oozing of blood was managed by compression either by the GB itself or by hemostatic gauze. The GB was removed through the epigastric port or the umbilical port. Intraabdominal tube drain at the sub-hepatic space was routinely inserted in all of our cases. Our threshold for conversion to open was any time passed more than ten minutes without progression.

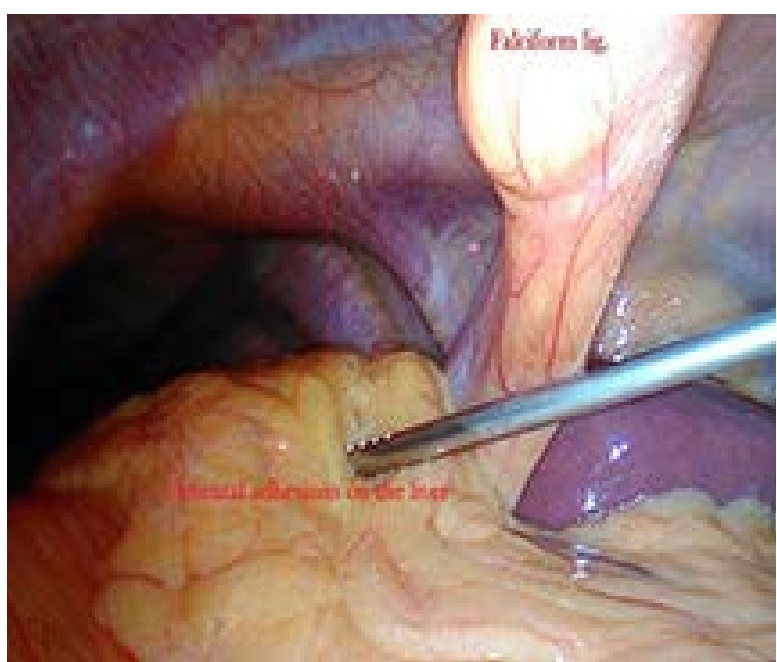

a

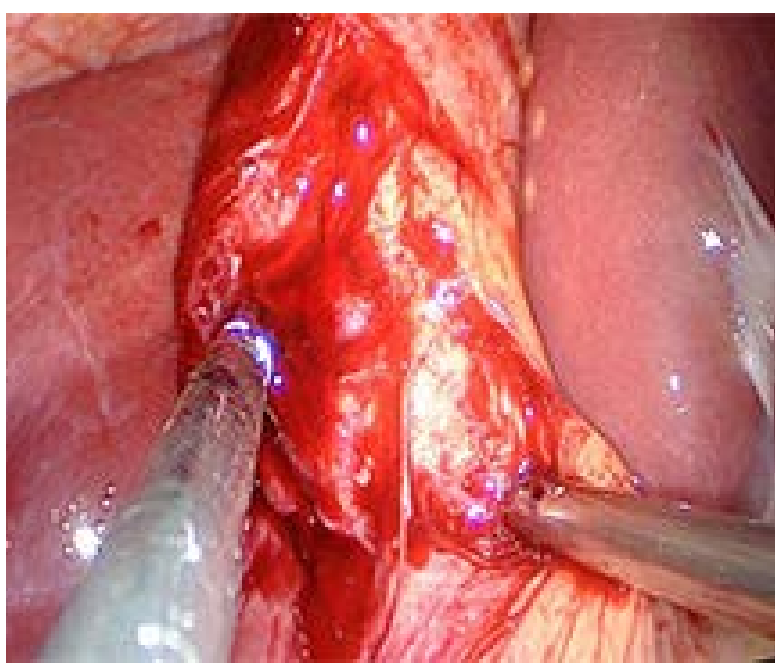

b

Image 3a,b: a- Adhesiolysis through left upper mid-clavicular port

b- Dissection of the Calot triangle through the two left ports.

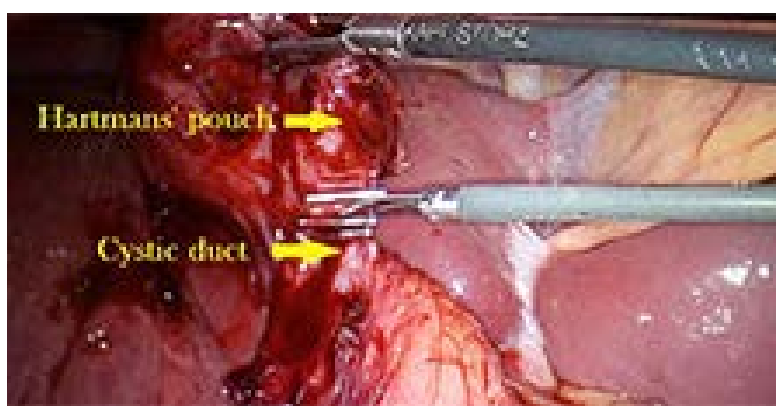

Image 4: Clipping and dividing cystic duct using left approach.

\section{Follow up:}

Patients were kept postoperatively nothing per mouth until the intestinal sounds became audible and the abdominal drain was removed when it drained less than $30 \mathrm{cc}$ per day (non-bile tinged). The first follow up visit was done after 1 week of patient's discharge and then once per month for three months. The least follow up was 3 months. 


\section{Results}

Out of the 24 patients, there were 13 males and 11 females with male to female ratio $1.2: 1$, age ranged from 42 years old to 67 years old with mean of 52.26 years and the body mass index (BMI) ranged from 27 to 35 with mean of 33.41 .

8 patients had hypertension and 5 had diabetes mellitus type 2 and 2 patients had ischaemic heart disease. The main presenting symptoms were epigastric and right hypochondrium pain in all patients and the pain was associated with vomiting in $12.5 \%$ (Table 1).

Table 1: Patients' characteristics and co-morbid conditions

\begin{tabular}{lcc}
\hline & Number & Percentage \\
\hline $\begin{array}{l}\text { Total number of } \\
\text { patients }\end{array}$ & 24 & $100 \%$ \\
Age by years (Mean) & 52.26 & \\
Sex: & & \\
Male & 13 & $54 \%$ \\
Female & 11 & $46 \%$ \\
BMI (Mean) & 33.41 & \\
Co-morbidities (Total) & 15 & $63 \%$ \\
-Hypertension & 8 & $33.3 \%$ \\
-Diabetes Mellitus & 5 & $20.8 \%$ \\
-Ischaemic heart disease & 2 & $8.3 \%$ \\
Presenting symptoms: & & \\
-Epigastric and right & 24 & $100 \%$ \\
hypochondrium pain & & \\
-Associated vomiting & 3 & $12.5 \%$ \\
\hline
\end{tabular}

Three patients (12.5\%) had previous upper abdominal surgeries for peptic ulcer disease and for morbid obesity ( 1 was open surgery and 2 were laparoscopic). Five patients (20.8\%) had history of obstructive jaundice and underwent Endoscopic Retrograde Cholangiopancreatography (ERCP) with stone extraction and placement of common bile duct (CBD) stent. Three patients (12\%) had recurrent attacks of cholangitis and passed stones spontaneously and their MRCP was negative for CBD stones or strictures before cholecystectomy.

Nineteen patients (79\%) were admitted with acute cholecystitis with failed conservative treatment and then underwent emergency LC 3-7 days from the start of the attack. Three patients (12\%) underwent emergency LC for perforated and gangrenous cholecystitis. One patient (4\%) underwent elective LC and was diagnosed intra-operatively to have acute on top of chronic calcular cholecystitis and 1 patient (4\%) was Mirizzi's syndrome type I (Table 2).
Table 2: Predisposing factors for difficult LC

\begin{tabular}{|c|c|c|}
\hline & Number & Percentage \\
\hline $\begin{array}{l}\text { Previous upper abdominal } \\
\text { surgery }\end{array}$ & 3 & $12.5 \%$ \\
\hline Previous ERCP & 5 & $20.8 \%$ \\
\hline Recurrent cholangitis & 3 & $12.5 \%$ \\
\hline Acute cholecystitis & 15 & $62.5 \%$ \\
\hline $\begin{array}{l}\text { Perforated and or } \\
\text { gangrenous GB }\end{array}$ & 3 & $12 \%$ \\
\hline $\begin{array}{l}\text { Acute on top of chronic } \\
\text { cholecystitis (intra- } \\
\text { operative diagnosis) }\end{array}$ & 1 & $4 \%$ \\
\hline Mirizzi's syndrome & 1 & $4 \%$ \\
\hline
\end{tabular}

The operative time ranged from 100 to 180 minutes with mean of 135 minutes. There were no significant blood loss or other intra-operative complications encountered in any of the patients in this study. Conversion to open surgery was done in one patient (4\%) with unclear biliary anatomy which proved to be Mirizzi's syndrome and subtotal cholecystectomy was done at the level of Hartman's pouch. Two patients (8.3\%) in this study had port site infection and were treated by local antibiotic ointment and 1 patient (4\%) had chest infection on the 3rd postoperative day. Postoperative bile leak was not detected in any of our patients and hospital stay ranged from 2 to 5 days with mean of 3.2 days (Table 3 ).

Table 3: Operative time, conversion rate, postoperative complications and pathology

\begin{tabular}{lcc}
\hline & Number & Percentage \\
\hline $\begin{array}{l}\text { Operative time by } \\
\text { minutes (Mean) }\end{array}$ & 135 & \\
$\begin{array}{l}\text { Conversion to open } \\
\text { surgery }\end{array}$ & 1 & $4 \%$ \\
$\begin{array}{l}\text { Postoperative } \\
\text { complications: }\end{array}$ & & \\
$\begin{array}{l}\text { Port site infection } \\
\text { Chest infection }\end{array}$ & 2 & $8.3 \%$ \\
$\begin{array}{l}\text { Bile leak } \\
\text { Pathology results: }\end{array}$ & 1 & $4 \%$ \\
Acute cholecystitis & 0 & $0 \%$ \\
GB gangrene & 21 & $87.5 \%$ \\
\hline
\end{tabular}

\section{Discussion}

Laparoscopic cholecystectomy for symptomatic GB diseases was introduced to the general surgery practice in the late $1980 \mathrm{s.}^{5,6}$ The conversion to open surgery is sometimes mandatory to avoid biliary and vascular injury and it is recorded from 5 to $20 \% .^{7-9}$ And this may be due to sever condensed adhesions around the GB and Calot's triangle, fibrosed contracted GB and GB gangrene. ${ }^{10}$ 
In the past, difficult cholecystectomies were converted to open and dealt by fundus first approach and subtotal cholecystectomy, and were considered safe and definitive surgery. ${ }^{11}$

We believe that difficult LC is difficult in open surgery as well, or may be more difficult in high BMI patients due to difficult exposure. Moreover, open surgery has higher morbidity and postoperative complications than LC.

There are several techniques described in the literature for LC in difficult cases with dense adhesions and unclear biliary anatomy. Harilingam et al. described laparoscopic retrograde subtotal cholecystectomies in 993 patients and their conversion rate to open surgery was $1.3 \%$. They started the procedure by opening the fundus of GB down till the Hartman's pouch and ligated it and in some cases they left the posterior wall of the GB and their bile leak incidence was $4.6 \% .^{12}$

Bile leak after laparoscopicsubtotal cholecystectomy is a common complication with reported incidence of $16 \% .13,14$

A dome down technique similar to laparoscopic retrograde cholecystectomy was described by Kassim et al, done in difficult LC cases and their conversion rate to open surgery was $8.3 \%$ without any bile duct injury recorded and the mean hospital stay was 2.5 days. ${ }^{15}$ In our series, the hospital stay was relatively longer with mean of 3.2 days which could be related to the preoperative hospital stay added for conservation in acute cholecystitis patients (48 hours).

From our point of view, retrograde LC is a good surgical option in difficult LC before converting to open surgery but with special care and early detection of any bile duct injury because in some cases the surgical plane is not always clear between the posterior wall of GB and the major bile ducts.

Another technique described by Sinha et al, used in difficult LC of acute cholecystitis is called finger port approach as they widened the right hypochondrium port and introduced their forefinger to dissect the adhesions on the gall bladder. Their mean conversion rate was $4.2 \%$ and their overall complications rate was $5.69 \% .{ }^{16}$

The limitation of this technique is that it cannot be applied to all patients especially the obese where the finger may not reach inside the abdomen. Our first experience using left approach LC was in a male patient with perforated GB with pericholecystic abscess surrounded by severe dense adhesions with omentum and transverse colon. The adhesiolysis and entry inside the pericholecystic abscess was difficult and unsafe with the conventional technique, so we introduced the two left mid-clavicular ports and went easily into the abscess just beneath the falciform ligament.

There are several advantages of our technique, firstly that it facilitates the visualization of the adhesions on the liver and GB when the scope is shifted to the upper left mid-clavicular port. Secondly, it is technically easier to deal with adhesion from up downwards rather than traction from downwards in the conventional technique. In addition to the safety added in the introduction of ports in the least part of the abdomen that contains adhesions from previous abdominal surgeries.

The potential drawbacks of this study are related to the sample size and the selective nature of patients. The limitation of our technique is that it will not add value in dealing with difficulty related to anomalies in the biliary or vascular system or related to severe adhesions in the Calot's triangle. Moreover, liver kyphosis and left lobe enlargement may be obstacles in using our technique.

\section{Conclusion}

The use of left approach technique in LC for difficult cases of acute cholecystitis is effective and safe and further studies should be done to include larger number of patients with different types of difficulties.

\section{References}

1. Sahu SK, Agrawal A, Sachan PK: Intraoperative Difficulties in laparoscopic cholecystectomy. Jurnalul de Chirurgie (Iaşi) 2013; 2: 149-155.

2. Kanakala $V$, Borowski DW, Pellen MG, Dronamraju SS, Woodcock SA, SeymourK, et al: Risk factors in laparoscopic cholecystectomy. A multivariate analysis. Int J Surg 2011; 9: 318323.

3. Hussain A: Difficult laparoscopic cholecystectomy: Current evidence and strategies of management. Surg Laparosc Endosc Percutan Tech 2011; 21: 211-217.

4. De Pouvourville G, Ribet-Reinhart N, Fendrick $M$, Houry S, Testas $P$, Huguier M: A prospective comparison of the costs and morbidity of laparoscopic versus open cholecystectomy. Hepatogastroenterology 1997; 44: 35-39.

5. Begos DG, Modlin IM: Laparoscopic cholecystectomy: From gimmick to gold standard. J Clin Gastroenterol 1994; 19: 325330. 
6. Blum CA, Adams DB: Who did the first laparoscopic cholecystectomy? J Minim Access Surg 2011; 7: 165-168.

7. Bailey RW, Zucker KA, Flowers JL, Scovill WA, Graham SM, Imbembo AL: Laparoscopic cholecystectomy: Experience with 375 consecutive patients. Ann Surg 1991; 214: 531-534.

8. Comitalo JB: Laparoscopic cholecystectomy and newer techniques of gallbladder removal. JSLS 2012; 16: 406-612.

9. Gurusamy KS, Davidson C, Gluud C, Davidson BR: Early versus delayed laparoscopic cholecystectomy for people with acute cholecystitis. Cochrane Database Syst Rev 2013; 6: CD005440.

10. Kama NA, Doganay M, Dolapci M, Reis E, Atli $M$, Kologlu M: Risk factors resulting in conversion of laparoscopic cholecystectomy to open surgery. Surg Endosc 2001; 15: 965-968.

11. Katsohis C, Prousalidis J, Tzardinoglou E, Michalopoulos A, Fahandidis E, Apostolidis S, et al: Subtotal cholecystectomy. HPB Surg 1996; 9: 133-136.
12. Harilingam MR, Shrestha AK, Basu S: Laparoscopic modified subtotal cholecystectomy for difficult gall bladders: A single-centre experience. J Min Access Surg 2016; 12: 325-329.

13. Philips $J A$, Lawes DA, Cook AJ, Arulampalam TH, Zaborsky A, Menzies $D$, et al: The use of laparoscopic subtotal cholecystectomy for complicated cholelithiasis. Surg Endosc 2008; 22: $1697-1700$.

14. Horiuchi A, Watanabe Y, Doi T, Sato K, Yukumi $S$, Yoshida M, et al: Delayed laparoscopic subtotal cholecystectomy in acute cholecystitis with severe fibrotic adhesions. Surg Endosc 2008; 22: 2720-2723.

15. Kassem MI, Elzeiny MM, El-haddad HM, AbuNasr AA.: Dome down approach for difficult laparoscopic cholecystectomy. Egypt $\boldsymbol{J}$ Surg 2015; 34: 203-209.

16. Sinha R, Sharma N: Difficult laparoscopic cholecystectomy in acute cholecystitis: Use of 'finger port', a new approach. HPB (Oxford) 2003; 5: 133-136. 